\title{
Actinic Cheilitis: Clinical Characteristics Observed in 75 Patients and a Summary of the Literature of This Often Neglected Premalignant Disorder
}

\author{
Ana Maria de Oliveira Miranda, Thiago de Miranda Ferrari, Taiana Campos Leite, \\ Karin Soares Gonçalves Cunha, Eliane Pedra Dias \\ Post-Graduate Program in Pathology, Medical School, Fluminense Federal University, Niterói, Brazil \\ Email: anamiranda3@hotmail.com
}

Received 13 October 2014; revised 10 November 2014; accepted 28 November 2014

Copyright (C) 2014 by authors and Scientific Research Publishing Inc.

This work is licensed under the Creative Commons Attribution International License (CC BY). http://creativecommons.org/licenses/by/4.0/

(c) (i) Open Access

\begin{abstract}
Actinic cheilitis can progress to squamous cell carcinoma in $20 \%$ of cases. The purpose of this study was to identify the clinical characteristics of 75 patients with actinic cheilitis and to summarise the current literature concerning actinic cheilitis. A total of 75 patients were evaluated over a 3-year period. The medical history, physical examination results and images were collected from each patient. Demographic data were collected and analysed. To review the literature, the relevant data were collected from scientific journals in the last 30 years. The mean age of the patients was 56 years old; 42 patients $(56 \%)$ were female, and 66 patients $(88 \%)$ were white. Nineteen $(25.3 \%)$ patients reported at least one symptom, including pain, burning and itching. Sixty-five (86.7\%) patients presented actinic cheilitis only in the lower lip. All of the patients reported sun exposure, and $44(58.6 \%)$ patients were exposed for more than 10 years. The main clinical aspects investigated and analysed included dryness $(100 \%)$, flaking $(72 \%)$ and white lesions $(57.3 \%)$. Lip assessment is extremely important in medical and dental care. From the 15 lesions assessed in the presence of actinic cheilitis, the most common clinical characteristics observed were dryness, flaking and white lesions. It is imperative to know the clinical aspects that may be encountered in actinic cheilitis in order to achieve early diagnosis, thus avoiding lip squamous cell carcinoma transformation.
\end{abstract}

\section{Keywords}

Actinic Cheilitis, Lip Cancer, Sun Exposure, Premalignant Disorder 


\section{Introduction}

Cheilitis refers to an inflammatory process of the lips that has many causes. Among the different types of cheilitis, actinic cheilitis (AC) is the most frequent and important and is caused by solar radiation. Most authors agree that AC it is a potentially malignant disorder or an incipient form of carcinoma that may develop into squamous cell carcinoma (SCC) of the lips [1]-[3]. The diagnosis of AC is important because the initial clinical manifestations are subtle and do not necessarily reflect the extent of damage to the epithelial and connective tissues [2]. In addition to clinical exams, cytopathology may contribute to the identification of epithelial dysplasia [4]. Another auxiliary method of diagnosis is the videoroscopic exam, similar to dermatoscopy, which is noninvasive, allowing the in vivo evaluation of the structures of epidermis that are invisible to the naked eye [5] [6]. Confocal microscopy (RCM), which is a non-invasive image technique, was recently applied to patients with clinical suspicion of AC [7]. Other studies have evaluated the usefulness of tissue autofluorescence in AC diagnosis and concluded that tissue autofluorescence image systems in association with clinical examinations are a useful technique for AC diagnosis [8]. The histopathological exam is the gold standard for the conclusive diagnosis of AC [2] [9]. To establish the histopathological diagnosis of AC, some morphological parameters must be considered, including acanthosis, thicker keratin layer [parakeratosis or orthokeratosis], solar elastosis [the most consistent histological finding], the presence of inflammatory infiltration and perivascular inflammation. However, other common findings may be encountered, such as dyskeratosis, hyperplasia and hypotrophy. The histological aspects vary according to the grade of epithelial dysplasia, especially with respect to the presence of hyperchromic enlarged cellular nuclei with irregular shapes and occasional atypical mitosis [1] [2] [4]. Many studies have been conducted with the purpose of identifying prognostic markers that identify lesions with a greater potential for malignant transformation. However, a predictive prognostic marker for these malignant transformations in AC has yet to be identified. Research has been focused thus far on the evaluation of the immunohistochemical expression of the p53 protein [10]-[13]. Other immunohistochemical markers have also been used, including Bax, Bcl-2, the cell proliferation marker Ki-67 [12], MDM2 [10], p21 [11], p63 proteins [14], hMLH1 and hMSH2 [15]. Fibroblast and mast cell densities have also been studied, suggesting that these cells may contribute to the tumour progression in its invasion front [16] [17].

Because AC may develop into SCC and subsequently metastasise, patients must undergo a thorough investigation and long-term follow-up. These patients require aggressive treatment, according to the clinical evolution and histologic features [2] [18] [19]. Histopathological results will determine the type of approach, and treatment modalities are numerous, each with its own advantages and disadvantages [19]. One of the most common treatments is vermilionectomy, and other modalities include $\mathrm{CO}_{2}$ or erbium lasers, electrodessication, topical application of 5-fluorouracil tretinoin, topical imiquimod, trichloroacetic acid chemical peel, photodynamic therapy using 5-aminolevulinic acid (5-ALA) and thulium laser [10] [19]-[22]. After concluding treatment, the patient must undergo rigorous follow-up and periodic exams with clinical control consultations because remaining lesions may change their appearance [22]. The best prevention for AC is the use of sunscreen and the avoidance of sun exposure [1]. The purpose of this study was to identify the clinical aspects of 75 patients with actinic cheilitis and to present the most important and recent findings regarding the etiopathogenesis, prevalence, clinical and histopathological features, diagnosis and treatment of AC.

\section{Material and Methods}

Between the years 2010 and 2013, in a consecutive manner, 75 patients with clinical diagnoses of AC were submitted to specific protocols for the care and monitoring of patients with actinic cheilitis at the outpatient clinic of Oral Diagnosis, Antonio Pedro University Hospital, Medicine School of Federal Fluminense University. In order to be included in the study, patients must have received clinical AC diagnosis, and must have reported sun exposure history; exclusion criterion was the clinical presence of other lesions on the lips, other than AC. Before initiating clinical examination, all patients were presented to a detailed explanation on the methodology to be employed and those who accepted to participate in this study signed an informed consent. These patients were evaluated over a three-year period, and the patients' medical history, physical examination and image results for the affected lip were considered. During the medical history, age, gender, race, habits and symptoms were recorded. During physical examination, particular attention was paid to dryness, flaking, white lesions, diffuse blurring between the border of the lip and the skin, loss of elasticity, erythema, brown staining, hardening of the lip, diffuse increase in the volume of the lip, focal increase the volume of the lip, focal blurring between the 
border of the lip and the skin, fissures, erosions, ulcers and crust (Figure 1, Figure 2). This study was approved by the Antônio Pedro University Hospital Ethics Committee under the CAAE number 0107.0.250.000-09.

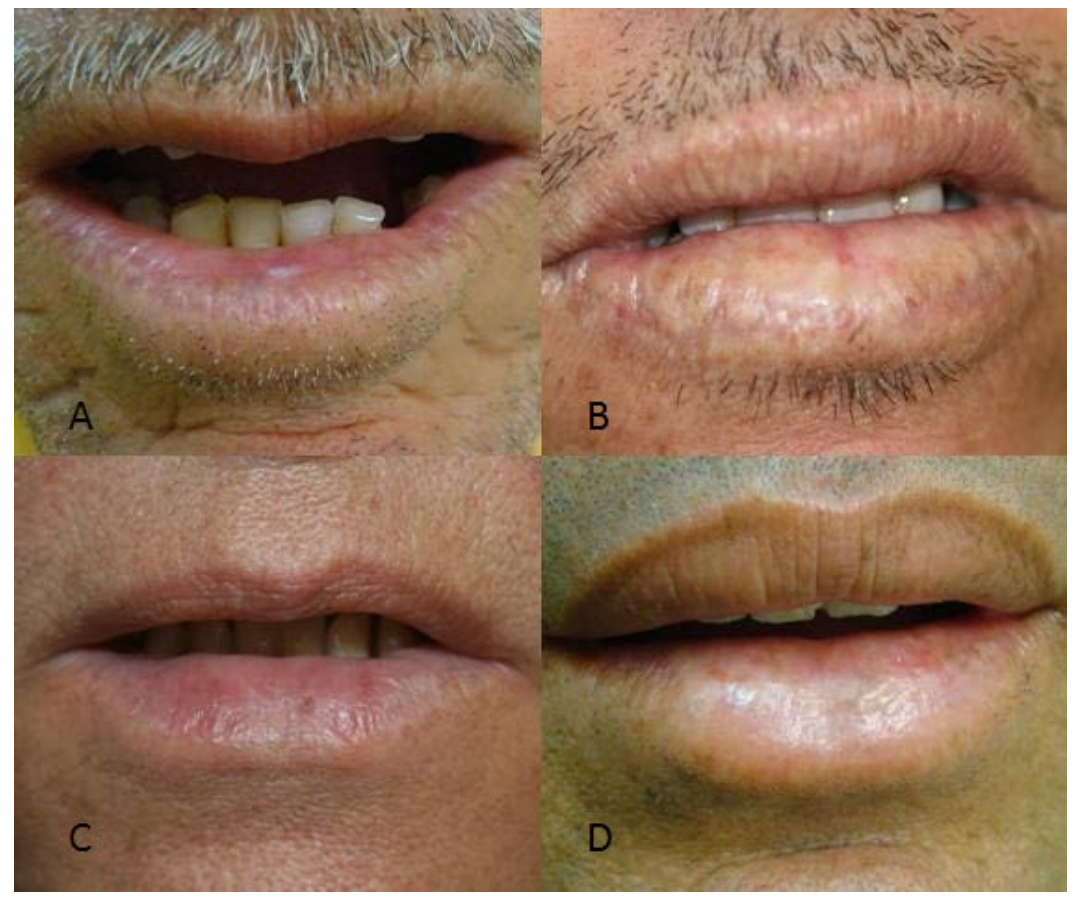

Figure 1. Actinic cheilitis: clinical characteristics. (A) White lesion; (B) White lesion; (C) Erythema; (D) Dryness and focal blurring between the border of the lip and the skin.

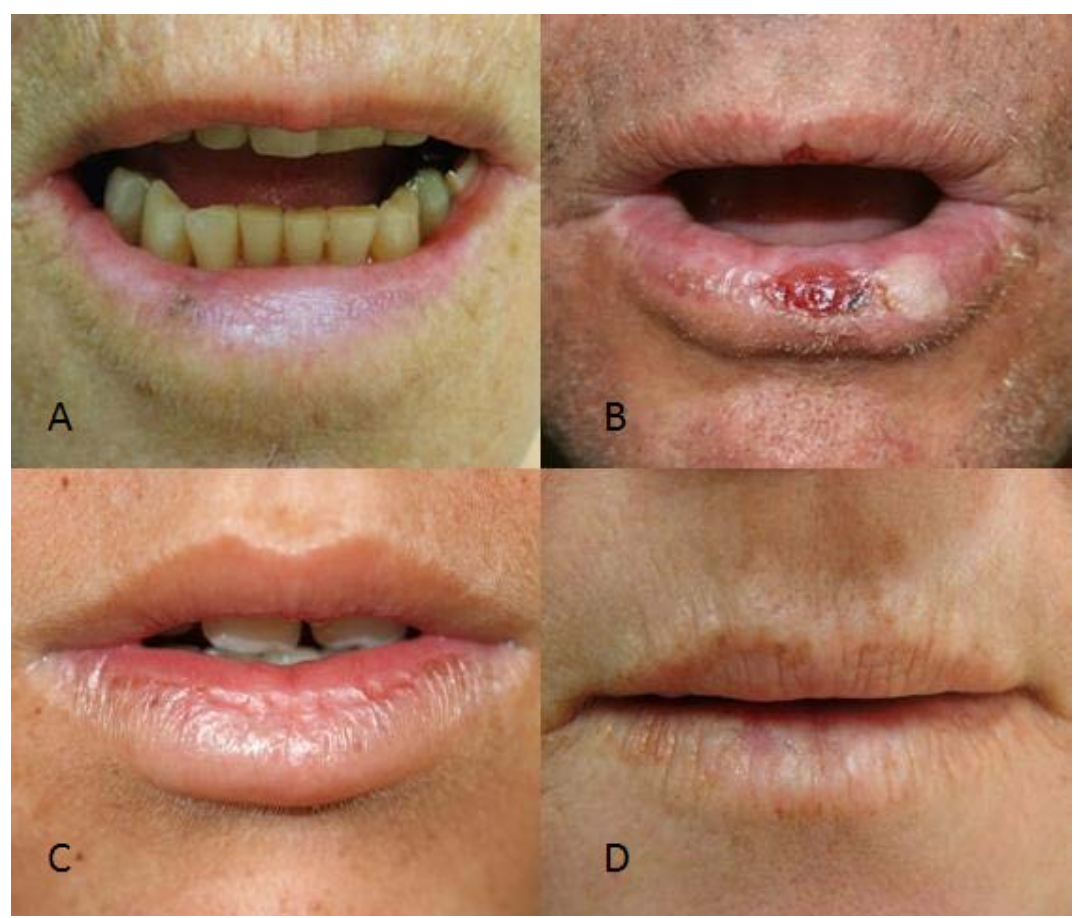

Figure 2. Actinic cheilitis: clinical characteristics. (A) Brown stain and diffuse blurring between the border of the lip and the skin; (B) Ulcer and white lesion; (C) Dryness and flaking; (D) Diffuse blurring between the border of the lip and the skin. 
For the summary of literature, we collected and analysed relevant data regarding the etiopathogenesis, prevalence, clinical presentation, histopathology, diagnosis and treatment of actinic cheilitis that were published in scientific journals in the last 30 years.

\section{Results}

The mean age of the AC patients was 56 years old (standard deviation $=15.13$ years old, minimum age $=10$ years old, median $=56$ years old, maximum age $=86$ years old), and $42(56 \%)$ patients were female. The proportion of men (44\%) and women (56\%) in the sample did not differ significantly $(\mathrm{p}>0.05$, binomial test: $\mathrm{p}=$ 0.356). Sixty-six (88\%) patients were white, and the binomial test indicated a statistically significant difference between the proportion of white individuals and the proportion of mixed-race individuals (p-value $=0)$. Sixtyfour patients (85\%) were non-smokers. All patients reported sun exposure, and 44 (58.6\%) were exposed for more than 10 years, 33 (44\%) related to an outdoor occupation. Nineteen (25\%) patients reported symptoms, including burning $(n=13 ; 17.3 \%)$, itching $(n=5 ; 6.6 \%)$ and pain $(n=4 ; 5.3 \%)$. Only $10(13.3 \%)$ patients exhibited AC in both the upper and lower lip (Table 1). The clinical investigation revealed as the following common clinical observations: dryness (100\%), flaking (72\%), white lesions (57\%) and diffuse blurring between the border of the lip and the skin (55\%) (Table 2).

\section{Table 1. Distribution of demographic data of the sample.}

\begin{tabular}{ccc}
\hline & $\mathbf{n}$ & \% \\
\hline Outdoor occupation & 33 & 44 \\
Symptoms & 19 & 25.3 \\
Burning & 13 & 17.3 \\
Itching & 5 & 6.6 \\
Pain & 4 & 13.3 \\
Upper and lower lip & 10 & 86.7 \\
\hline
\end{tabular}

Table 2. Distribution of clinical aspects found in 75 patients with actinic cheilitis.

\begin{tabular}{|c|c|c|}
\hline Clinical aspect & Number of patients & $\%$ of sample \\
\hline Dryness & 75 & 100 \\
\hline Flaking & 54 & 72 \\
\hline White lesion & 43 & 57.3 \\
\hline Diffuse blurring between the border of the lip and the skin & 41 & 54.7 \\
\hline Loss of elasticity & 38 & 50.7 \\
\hline Erythema & 36 & 48 \\
\hline Brown stain & 31 & 41.3 \\
\hline Hardening of lip & 18 & 24 \\
\hline Diffuse increase of the volume of the lip & 17 & 22.7 \\
\hline Focal increase of the volume of the lip & 15 & 20 \\
\hline Focal blurring between the border of the lip and the skin & 15 & 20 \\
\hline Fissure & 10 & 13.3 \\
\hline Erosion & 6 & 8 \\
\hline Ulcer & 4 & 5.3 \\
\hline Crust & 3 & 4 \\
\hline
\end{tabular}




\section{Discussion}

Lip SCC usually arises from pre-existing untreated cases of AC or may simply co-exist with AC [21] [23]. Although it is accepted that $10 \%$ to $20 \%$ of AC cases undergo malignant transformation, the time span for this transformation to occur is unpredictable ( 1 - 20 years). The incidence of progression is alarming, and early diagnosis is mandatory [2]. Therefore, AC needs to be diagnosed early and followed-up well [1]. The first step to be able to make the correct diagnosis is to understand the clinical characteristics of AC. Our study was based on this idea. There is no study in the current AC literature that reports the prevalence of AC in the world population; however, there are a number of studies analysing AC prevalence in specific populations, including male fishermen, field workers, or elderly individuals. These studies have reported prevalence ranging from $0.2 \%$ to $43 \%$ [3] [24] [25]. Our study observed AC seven times more often in the lower lip, similar to other studies. AC is frequently found in white individuals, although it is not exclusive to this group. AC usually manifests after the age of 45 years old and has a male predominance, with the male to female ratio ranging from 1.77:1 to 10:1 [1] [2] [24]-[26]. The results of our study were similar to those in the literature with respect to the mean of age at diagnosis and the skin colour of the participants; the mean age in this study was 56 years old, and $88 \%$ of the participants were white subjects. According to the literature, AC is predominantly found in males [2] [25], but in this study, we had a larger number of females. This discrepancy may be because these patients were treated at a referral hospital, where females seek and accept treatment more frequently than males. Additionally, women are currently exposed to the sun more frequently and play more outside sports than in the past.

Two forms of AC have been described in the literature: acute and chronic. The acute form is less common and is more frequent in young individuals. The acute form is associated with episodes of intense sun exposure and is characterised by oedema, redness, fissures, ulcerations, and vesicles. This form is usually self-limited and disappears after the removal of causal agents [27]. The chronic form occurs due to continuous sun exposure, and all participants in this study exhibited the chronic form of AC. The lip is commonly dry and atrophic with scaly areas, which may or not be uniform; keratotic white or grey areas with or without associated red areas; white lesions, red areas, fissures, erosions or superficial ulcers; and blurring between the border of the lip and the skin [1] [27]. AC is usually asymptomatic, which is one of the reasons that patient delay seeking professional assistance. In this study, only 19 (25.3\%) of patients reported any symptoms; these data are similar to the data reported by Cavalcante et al. (2008), who indicated that $34.48 \%$ of patients do not report any symptoms. Given the risk of malignant transformation of AC, it is very important to increase awareness. Professionals, including dentists and doctors, must be able to identify and evaluate the clinical characteristics presented by patients, even if the patient does not complain of any symptoms. The establishment of awareness programs by the government, medi$\mathrm{cal} / \mathrm{dental}$ associations and colleges would further help disseminate knowledge of the existence of this potentially malignant disorder to prevent the onset or worsening of AC.

The differential diagnosis of AC includes hyperplastic chronic candidiasis, mucositis, pseudomembranous candidiasis, lichen planus, as well as other types of cheilitis, including the exfoliative, glandular, granulomatous, and contact types [28]. An understanding of the clinical characteristics of AC is critical in making the differential diagnosis. AC exhibits slow progression, which makes it difficult to notice and leads to it being easily misdiagnosed as a physiological aging process. Clinically, AC may present as localised or diffuse lesions, the latter being the most common. Clinical exam may reveal scaly areas, dryness, erythema and oedema; over time, the lips may exhibit fissures, rough areas, white lesions, and loss of elasticity. With time, ulcers, crusts, atrophy, and blurring forms between the border of the lip and the skin [1]-[3] [6]. Elevated lesions, red areas, ulcers, and bleeding are signs of probable malignancy [2]. However, the clinical exam has its limits. Some lesions are hard to identify or ambiguous; small erosions can be confused with erythema, and fissures can be confused with deeper grooves. Early on, these lesions cannot be detected by the naked eye, similar to white lesions, erythema and some others lesions. Moreover, it is not possible to predict the presence of epithelial dysplasia based solely on clinical exam; a lesion with a benign appearance can be an initial stage of SCC. As AC is a heterogeneous lesion, it is important to record the precise site at which each lesion was found in clinical exam; however, no protocols in the literature are available.

In 2008, it was reported that the most frequent clinical characteristic in AC patient was dryness [1]. In our study, consistent with this report, we observed that all patients exhibited dryness during their first examination, which subsided after education regarding hydration and protection. Flaking was also very frequent and was found in all ages; as with dryness, flaking improved after hydration. White lesions in the form of spots or 
plaques were more frequently observed in our study than in the study by Cavalcante et al. [1], and generally more than one white lesion was found in each patient. We could observe that the blurring of the limit between the lip and skin occurs progressively; thus, in some patients it was possible to see only some parts obscured by the blurring, and in other patients, this blurring extended throughout the lip. Diffuse blurring between the border of the lip and the skin occurred frequently in older patients, as well as the loss of elasticity. In young patients, unlike in older patients, greater wrinkling was observed. Erythema was present in multifocal sites, varying in the amount of damage in the same patient as well as in the intensity of colour, shape and size. Brown stains were observed in all ages and were independent of the presence of other lesions. Less often, hardening of the lip was noted, generally in older people. The least frequent lesions were fissures, erosion, ulcers and crust; ulcers and crusting were normally associated with cases of poor prognosis. Therefore, it is important to visualise as well as possible the size, format, and precise location of each lesion on the lip, and if it is possible, to record the images of each lesion to make an effective comparison during the patient's follow up.

Few papers propose a clinical classification of chronic AC. In a study of the prevalence of AC, the authors mention a subdivision of AC according to severity level as mild or initial (dry and scaly areas), moderate (more severe dry and scaly areas and fissures), and severe (hardening of the lip, blurring between the border of the lip and the skin, ulcers, and crusts, as well as the aforementioned previous alterations) [3]. The patients in this sample were distributed based on this classification: 25 (33.3\%) cases were mild, 3 (4\%) cases were moderate and 47 (62.7\%) cases were severe. However, there was some difficulty in using this clinical classification because some lesions frequently found in this study were not mentioned by this classification, including white lesions, erythema and brown stains. The classification refers to blurring of the limit between the lip and skin but does not specify whether it is focal or diffuse, as was noted in the patients of this study. Furthermore, $32(42.6 \%)$ of the patients exhibited focal or diffuse increases in the volume of the lip, which was not considered by this classification. We believe that the presence of white lesions, erythema, and increased lip volume as well as the distinction between focal and diffuse blurring of the limit between the lip and the skin must be considered in the classification of AC, thereby aiding the clinician and specialist in the classification of this potentially malignant disorder.

\section{Conclusion}

This is a preliminar study, with the purpose of promoting a higher visibility of this potentially malignantlesion, encouraging new studies, especially regarding histopathological aspects of AC. Given that AC is a potentially malignant disorder that may develop into SCC in $20 \%$ of cases, AC must be correctly diagnosed as soon as possible so that the patient can receive proper treatment and long-term follow-up, as well as all relevant information regarding the prevention of worsening of the condition. Dryness, flaking and white lesions were the most commonly observed clinical characteristics, but no lesion can be neglected in AC. Many studies have been conducted; however, there remains much to be analysed to avoid the transformation of AC into carcinoma.

\section{Funding Source}

CNPq (Conselho Nacional de Desenvolvimento Científico e Tecnológico-National Counsil for Technological and Scientific Developement).

\section{Conflict of Interest}

The authors have no conflict of interest to declare.

\section{References}

[1] Cavalcante, A.S.R., Anbinder, A.L. and Carvalho, Y.R. (2008) Actinic Cheilitis: Clinical and Histological Features. Journal of Oral and Maxillofacial Surgery, 66, 498-503. http://dx.doi.org/10.1016/j.joms.2006.09.016

[2] Markopoulos, A., Albanidou-Farmaki, E. and Kayavis, I. (2004) Actinic Cheilitis: Clinical and Pathologic Characteristics in 65 Cases. Oral Diseases, 10, 212-216. http://dx.doi.org/10.1111/j.1601-0825.2004.01004.X

[3] da Silva, F.D., Daniel, F.I., Grando, L.J., Calvo, M.C., da Silva Rath, I.B. and Fabro, S.M.L. (2006) Estudo da prevalência de alterações labiais em pescadores da ilha de Santa Catarina; Prevalence of lipspathologies in fishermen of Santa Catarina Island. Revista Odonto Ciência, 21, 37-42.

[4] da Costa Fontes, K.B.F., Cunha, K.S.G., Rodrigues, F.R., da Silva, L.E., Dias, E.P., et al. (2013) Concordance between 
Cytopathology and Incisional Biopsy in the Diagnosis of Oral Squamous Cell Carcinoma. Brazilian Oral Research, 27, 122-127.

[5] Calandro, T.L.L., Conde, D.C., Campos, I.T. and Dias, E.P. (2006) A utilização da videoroscopia na investigação de lesões orais; the use ofvideoroscopy for the oral lesionsinvestigation. Revista Brasileira de Odontologia, 66, 170-176.

[6] Conde, D.C., Calandro, T.L.L., Campos, I.T. and Dias, E.P. (2010) The Intraoral Video Camera: A Diagnostic Tool in the Exam of Patient with Increased Oral Cancer Risk. Revista de Clínica e Pesquisa Odontológica, 6, 49-55.

[7] Ulrich, M., González, S., Lange-Asschenfeldt, B., Roewert-Huber, J., Sterry, W., Stockfleth, E., et al. (2011) Non-Invasive Diagnosis and Monitoring of Actinic Cheilitis with Reflectance Confocal Microscopy. Journal of the European Academy of Dermatology and Venereology, 25, 276-284. http://dx.doi.org/10.1111/j.1468-3083.2010.03777.x

[8] Takahama Junior, A., Kurachi, C., Cosci, A., Pereira Faustino, I.S., Camisasca, D.R., da Costa Fontes, K.B.F., et al. (2013) Usefulness of Tissue Autofluorescence Imaging in Actinic Cheilitis Diagnosis. Journal of Biomedical Optics, 18, Article ID: 76023. http://dx.doi.org/10.1117/1.JBO.18.7.076023

[9] Williams, P.M., Poh, C.F., Hovan, A.J.S. and Rosin, M.P. (2008) Evaluation of a Suspicious Oral Mucosal Lesion. Journal of the Canadian Dental Association, 74, 275-280.

[10] Freitas, M.C.A., Ramalho, L.M.P., Xavier, F.C.A., Moreira, A.L.G. and Reis, S.R.A. (2008) p53 and MDM2 Protein Expression in Actinic Cheilitis. Journal of Applied Oral Science, 16, 414-419. http://dx.doi.org/10.1590/S1678-77572008000600011

[11] Martínez, A., Brethauer, U., Borlando, J., Spencer, M.L. and Rojas, I.G. (2008) Epithelial Expression of p53, mdm-2 and p21 in Normal Lip and Actinic Cheilitis. Oral Oncology, 44, 878-883. http://dx.doi.org/10.1016/j.oraloncology.2007.11.008

[12] Martínez, A., Brethauer, U., Rojas, I.G., Spencer, M., Mucientes, F., Borlando, J., et al. (2005) Expression of Apoptotic and Cell Proliferation Regulatory Proteins in Actinic Cheilitis. Journal of Oral Pathology \& Medicine, 34, 257262. http://dx.doi.org/10.1111/j.1600-0714.2004.00299.x

[13] Souza, L.R., Fonseca-Silva, T., Pereira, C.S., Santos, E.P., Lima, L.C., Carvalho, H.A., et al. (2011) Immunohistochemical Analysis of p53, APE1, hMSH2 and ERCC1 Proteins in Actinic Cheilitis and Lip Squamous Cell Carcinoma. Histopathology, 58, 352-360. http://dx.doi.org/10.1111/j.1365-2559.2011.03756.x

[14] Xavier, F.C.A., Takiya, C.M., Reis, S.R.A. and Ramalho, L.M.P. (2009) p63 Immunoexpression in Lip Carcinogenesis. Journal of Molecular Histology, 40, 131-137. http://dx.doi.org/10.1007/s10735-009-9223-4

[15] Sarmento, D.J.S., Almeida, W.L., Miguel, M.C.C., Queiroz, L.M.G., Godoy, G.P., Cruz, M.C.F.N., et al. (2013) Immunohistochemical Analysis of Mismatch Proteins in Carcinogenesis of the Lower Lip. Histopathology, 63, 371-377. http://dx.doi.org/10.1111/his.12197

[16] Freitas, V.S., Andrade, S.P.P., Freitas, R.A., Pinto, L.P. and Souza, L.B. (2011) Mast Cells and Matrix Metalloproteinase 9 Expression in Actinic Cheilitis and Lip Squamous Cell Carcinoma. Oral Surgery, Oral Medicine, Oral Pathology, Oral Radiology and Endodontics, 112, 342-348. http://dx.doi.org/10.1016/j.tripleo.2011.02.032

[17] Souza, L.R., Fonseca-Silva, T., Santos, C.C.O., Oliveira, M.V.M., Corrêa-Oliveira, R., Guimarães, A.L.S., et al. (2010) Association of Mast Cell, Eosinophil Leucocyte and Microvessel Densities in Actinic Cheilitis and Lip Squamous Cell Carcinoma. Histopathology, 57, 796-805. http://dx.doi.org/10.1111/j.1365-2559.2010.03721.x

[18] Huber, M. and Terezhalmy, G. (2006) The Patient with Actinic Cheilosis. General Dentistry, 54, $274-282$.

[19] Shah, A.Y., Doherty, S.D. and Rosen, T. (2010) Actinic Cheilitis: A Treatment Review. International Journal of Dermatology, 49, 1225-1234. http://dx.doi.org/10.1111/j.1365-4632.2010.04580.x

[20] Ghasri, P., Adman, I.S., Petelin, A. and Zachary, C.B. (2012) Treatment of Actinic Cheilitis Using a 1,927-nm Thulium Fractional Laser. Dermatologic Surgery, 38, 504-507. http://dx.doi.org/10.1111/j.1524-4725.2011.02262.x

[21] Kornevs, E., Skagers, A., Tars, J., Bigestans, A., Lauskis, G. and Libermanis, O. (2005) 5 Year Experience with Lower Lip Cancer. Stomatologija, Baltic Dental and Maxillofacial Journal, 7, 95-98.

[22] Wood, N.H., Khammissa, R., Meyerov, R., Lemmer, J. and Feller, L. (2011) Actinic Cheilitis: A Case Report and a Review of the Literature. European Journal of Dentistry, 5, 101-106.

[23] Vieira, R.A., Minicucci, E.M., Marques, M.E. and Marques, S.A. (2012) Actinic Cheilitis and Squamous Cell Carcinoma of the Lip: Clinical, Histopathological and Immunogenetic Aspects. Anais Brasileiros de Dermatologia, 87, 105114.

[24] Corso, F.M., Wilde, C., Gouveia, L.O. and Ribas, M.O. (2006) Queilite Actínica: Prevalência na Clínica Estomatológica da PUCPR. Clin. Pesq. Odontol., 2, 277-281.

[25] Miranda, A.M.O., Soares, L.G., Ferrari, T.M., Silva, D.G., Falabella, M.E.V. and Tinoco, E.M.B. (2012) Prevalence of Actinic Cheilitis in a Population of Agricultural Sugarcane Workers. Acta Odontológica Latinoamericana, 25, 201206. 
[26] Ochsenius, G., Ormeño, A., Godoy, L. and Rojas, R. (2003) A Retrospective Study of 232 Cases of Lip Cancer and Pre Cancer in Chilean Patients. Clinical-Histological Correlation. Revista Médica de Chile, 131, 60-66.

[27] Cataldo, E. and Doku, H.C. (1981) Solar Cheilitis. Journal of Dermatologic Surgery and Oncology, 7, 989-995. http://dx.doi.org/10.1111/j.1524-4725.1981.tb00203.x

[28] Andrade, E.S.S., Sobral, A.P.V., Laureano Filho, J.R., Santos, M.E.S.M. and Camargo, I.B. (2009) Cheilitis Glandularis and Actinic Cheilitis: Differential Diagnoses-Report of Three Unusual Cases. Dermatology Online Journal, 15, 5. 
Scientific Research Publishing (SCIRP) is one of the largest Open Access journal publishers. It is currently publishing more than 200 open access, online, peer-reviewed journals covering a wide range of academic disciplines. SCIRP serves the worldwide academic communities and contributes to the progress and application of science with its publication.

Other selected journals from SCIRP are listed as below. Submit your manuscript to us via either submit@scirp.org or Online Submission Portal.
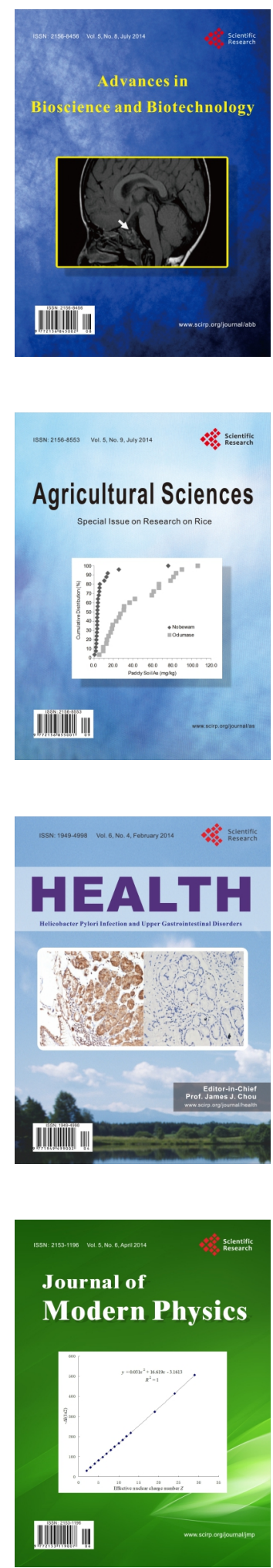
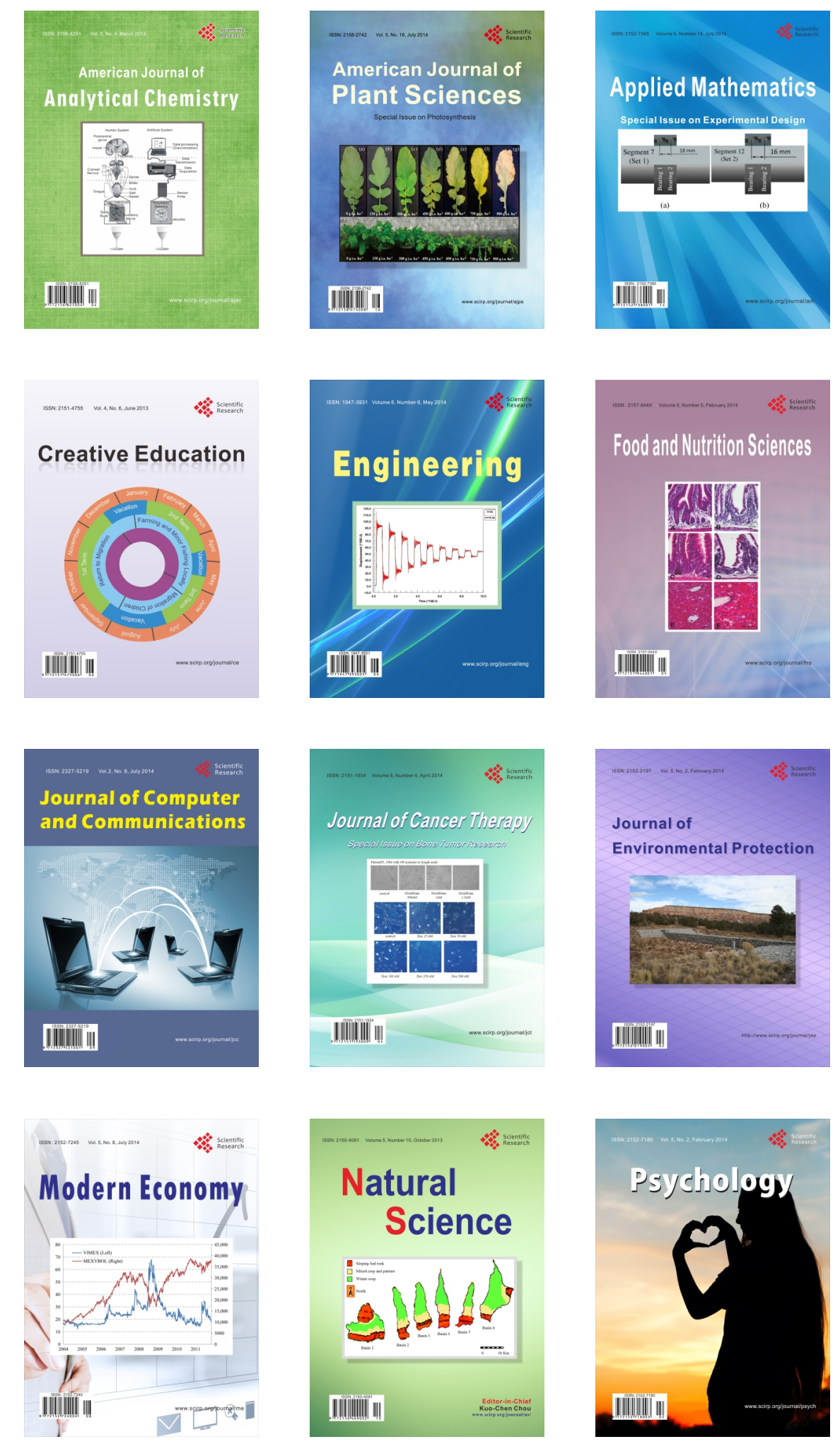